\title{
The EDOP Radar System on the High-Altitude NASA ER-2 Aircraft
}

\author{
Gerald M. Heymsfield, ${ }^{*}$ Steven W. Bidwell, $*$ I. Jeff Caylor, ${ }^{\dagger}$ Syed Ameen, ${ }^{\dagger}$ Shaun Nicholson, ${ }^{*}$ \\ Wayne Boncyk, ${ }^{\circledR}$ Lee Miller, ${ }^{\circledR}$ Doug Vandemark, $* *$ Paul E. Racette, ${ }^{*}$ and Louis R. Dod ${ }^{\dagger \dagger}$ \\ *Goddard Space Flight Center, Greenbelt, Maryland \\ ${ }^{\dagger}$ Science Systems and Applications, Inc., Lanham, Maryland \\ "TRW, Redondo Beach, California \\ ${ }^{\circledR}$ USGS, Eros Data Center, Sioux Falls, South Dakota \\ ${ }^{\&}$ Clemson University, Clemson, South Carolina \\ **Wallops Flight Facility, Wallops Island, Virginia \\ ${ }^{\dagger}$ Swales, Inc., Beltsville, Maryland
}

(Manuscript received 1 November 1995, in final form 16 February 1996)

\begin{abstract}
The NASA ER-2 high-altitude $(20 \mathrm{~km})$ aircraft that emulates a satellite view of precipitation systems carries a variety of passive and active (lidar) remote sensing instruments. A new Doppler weather radar system at $\mathrm{X}$ band $(9.6 \mathrm{GHz})$ called the ER-2 Doppler radar (EDOP) has been developed and flown on the ER-2 aircraft. EDOP is a fully coherent Doppler weather radar with fixed nadir and forward pointing ( $33^{\circ}$ off nadir) beams that map out Doppler winds and reflectivities in the vertical plane along the aircraft motion vector. Doppler winds from the two beams can be used to derive vertical and along-track air motions. In addition, the forward beam provides linear depolarization measurements that are useful in discriminating microphysical characteristics of the precipitation. This paper deals with a general description of the EDOP instrument including the measurement concept, the system configuration and hardware, and recently obtained data examples from the instrument. The combined remote sensing package on the ER-2, along with EDOP, provides a unique platform for simulating spaceborne remote sensing of precipitation.
\end{abstract}

\section{Introduction}

Airborne weather radar systems have played an important role in studying mesoscale convective systems (MCS) and other mesoscale and cloud-scale phenomena in recent years. These radars have provided an important tool to help understand kinematic and dynamical aspects of MCSs, such as the importance of the rear inflow jet, mesoscale up- and downdrafts, the sustinence of anvil precipitation, etc. (e.g., Smull and Houze 1987; Jorgensen et al. 1991). MCSs often have long lifetimes (12-24 h), cover large areas (several hundred kilometers), and advect considerable distances over their lifetime. As a result, ground-based radars may not be suitably located for high-resolution measurements of the vertical and horizontal structure of MCSs due to large radar slant ranges or from attenuation affects; or the MCSs are located over open ocean, which precludes ground-based radars. All airborne radar systems have, however, limited flight endurance that is sometimes short relative to MCS lifetimes.

Corresponding author address: Dr. Gerald M. Heymsfield, NASA/ GSFC, Code 912, Greenbelt, MD 20771.
Airborne Doppler radars have been previously operated on low-altitude ( $\sim 6 \mathrm{~km}$ maximum) aircraft and medium altitude $(\sim 12 \mathrm{~km}$ maximum $)$ aircraft. The most recent low-altitude $(\sim 6 \mathrm{~km})$ airborne Doppler systems at $\mathrm{X}$ band $(9-9.5 \mathrm{GHz})$ perform scanning about the aircraft longitudinal axis with looks $30-40^{\circ}$ forward and aft of the fuselage-normal plane to provide a quasi-dual-Doppler measurement of the winds (e.g., Jorgensen et al. 1994; Hildebrand et al. 1994). The low-altitude turboprop aircraft [National Oceanic and Atmospheric Administration (NOAA) WP-3D, and National Center for Atmospheric Research (NCAR) Electra] rely on primarily side-looking views by the radar and do not penetrate large updrafts and/or high reflectivity regions because of safety. The ER-2 Doppler radar is intended to fill some of this gap by overflying intense convection.

One of the most difficult measurements with Doppler radars has been the vertical air velocity $w$. For groundbased and low-altitude airborne radars, $w$ is calculated indirectly from upward or downward integration of the mass continuity equation using horizontal winds derived from horizontal divergence estimates (e.g., Ray 1990; Carbone et al. 1985). The problem is there are four unknowns (Cartesian wind components $u, v, w$, and hydrometeor fallspeed $v_{t}$ ) and three knowns (two radial velocity vectors taken from different viewing lo- 
cations and a fallspeed estimate typically based on the radar reflectivity). The horizontal winds are calculated by geometrically combining the two Doppler winds with $v_{t}$ removed, from multiple ground-based radars or different airborne views (forward and aft beams or orthogonal flight legs) at a common point in the threedimensional region being analyzed. Estimation of $w$ requires integration of the anelastic mass continuity equation with an upper or lower $w$ boundary condition. Errors in the derived horizontal and vertical winds can result from poor spatial resolution of the raw Doppler measurements used to compute mass divergence, inadequate estimates for the top and bottom boundary values used for $w$ and mass divergence, inaccuracy of the fallspeed estimates, etc. The low-altitude airborne systems provide somewhat higher resolution measurements than the ground-based systems, but the airborne measurements are subject to additional uncertainty due to the aircraft platform motions in a turbulent atmosphere. Vertical motions have also been calculated " $\mathrm{di}$ rectly" with NOAA WP-3D tail radar measurements using zenith and nadir azimuths to produce timeheight images of reflectivity and vertical motions (Marks and Houze 1987). These time-height images are readily interpreted as distance-height cross sections using the aircraft ground speed to convert the time axis to spatial distance.

The NCAR ELDORA system with two beams about $18.5^{\circ}$ forward and aft of the plane normal to the fuselage and with a relatively high scan rate, can map out horizontal winds in one linear flight track (Hildebrand et al. 1994). Flight plans are thus simplified, and spatial resolution is improved over the previous single-look P3 measurements that required orthogonal flight tracks; recently, the P3 has implemented dual antennas but with a single transmitter, which results in reduced along-track resolution (Jorgensen et al. 1994). Vertical velocities with ELDORA and the new P3 configuration are calculated in a manner similar to previous airborne and ground-based systems, except that the higher density of measurements and better coincidence in time provide less uncertainty in the derived winds. Using two aircraft simultaneously, called "quad Doppler," can reduce errors in $w$ further since the system of equations is overdetermined and it is not necessary to provide fallspeed estimates (Jorgensen et al. 1994).

Spaceborne precipitation radar systems in development have the capability to provide more direct measurements of precipitation structure than the current passive microwave radiometric instruments. Spaceborne radars have monumental problems in terms of spatial and/or Doppler velocity resolution due to the attendent high ground-track velocities. The first spaceborne radar for precipitation measurements will be the $\mathrm{K}_{\mathrm{u}}$-band (14 GHz) precipitation radar (PR) on the Tropical Rainfall Measuring Mission (TRMM) (Simpson et al. 1988). Two airborne down- looking radar systems that simulate spaceborne rain measurements, the Communication Research Laboratory (CRL) radar and Airborne Rain Mapping Radar (ARMAR), have been flown on the NASA DC-8 medium altitude aircraft. The CRL dual-frequency (10.5 and $35 \mathrm{GHz}$ ) incoherent radar-radiometer was configured for nadir-pointing DC-8 measurements in support of spaceborne radar algorithms (Kumagai et al. 1993). Rain estimates from the CRL radar have been evaluated along with microwave radiometric measurements (Wang et al. 1994). The ARMAR that transmits at $13.8 \mathrm{GHz}$ to simulate TRMM, is crosstrack scanning and has Doppler and polarization modes (Durden et al. 1994). The ARMAR can provide direct measures of vertical hydrometeor motions, but along- and cross-track winds cannot be obtained as for the low-altitude aircraft since multiple looks are not obtained from the same region. While the medium altitude of the DC- 8 is adequate to overfly many precipitation systems, there are often deep Midwest and tropical MCSs that cannot be safely penetrated by this aircraft during a single flight track. Convective regions of deep MCSs often have cloud tops that extend above $16 \mathrm{~km}$, convective cores with reflectivities larger than $50 \mathrm{dBZ}$, and peak updraft vertical velocities in excess of $15 \mathrm{~m} \mathrm{~s}^{-1}$ in the Tropics and $30 \mathrm{~m} \mathrm{~s}^{-1}$ in midlatitudes (e.g., Cotton and Anthes 1989).

A new dual-beam (nonscanning) Doppler weather radar system at $\mathrm{X}$ band $(9.6 \mathrm{GHz})$ called the ER-2 Doppler radar (EDOP) has been installed in the nose of the NASA ER-2. This aircraft flies at a nominal high altitude of $20 \mathrm{~km}$ with a ground speed of about 200 $\mathrm{m} \mathrm{s}^{-1}$, has a 7-h flight duration, and a payload capacity of about $1350 \mathrm{~kg}$. A downlooking radar on this highaltitude platform is desirable for several reasons. First, the ER-2 has a satellite-like perspective of MCSs and thunderstorms since it flies at an altitude virtually above all cloud tops, including high-level tropical thunderstorm anvils and intense Midwest thunderstorms with convective tops overshooting into the stratosphere. Even under these conditions, the ER-2 is a very stable platform. A downlooking radar from the ER-2 altitude directly measures the vertical reflectivity and wind structure from deep convective systems; this is generally not possible with other low- and medium-altitude aircraft. Because the ER-2 is relatively fast $\left(200 \mathrm{~m} \mathrm{~s}^{-1}\right)$ and has few aircraft traffic control restrictions at its cruising altitude, the ER-2 can readily overfly large MCSs in an uninterrupted fashion. A second important reason for a radar on the ER-2 is the valuable intercomparisons that can be made with the existing suite of remote sensing instruments for precipitation, clouds, and cloud radiation. The ER-2 can be configured with scanning radiometers at visible, near-infrared, and infrared wavelengths $(0.5-13 \mu \mathrm{m})$, microwave frequencies ranging from 10 to $325 \mathrm{GHz}$, and a nadir pointing backscatter lidar system (e.g., Kakar 1993; Griffin et al. 1994). This instrument suite has been valuable for 

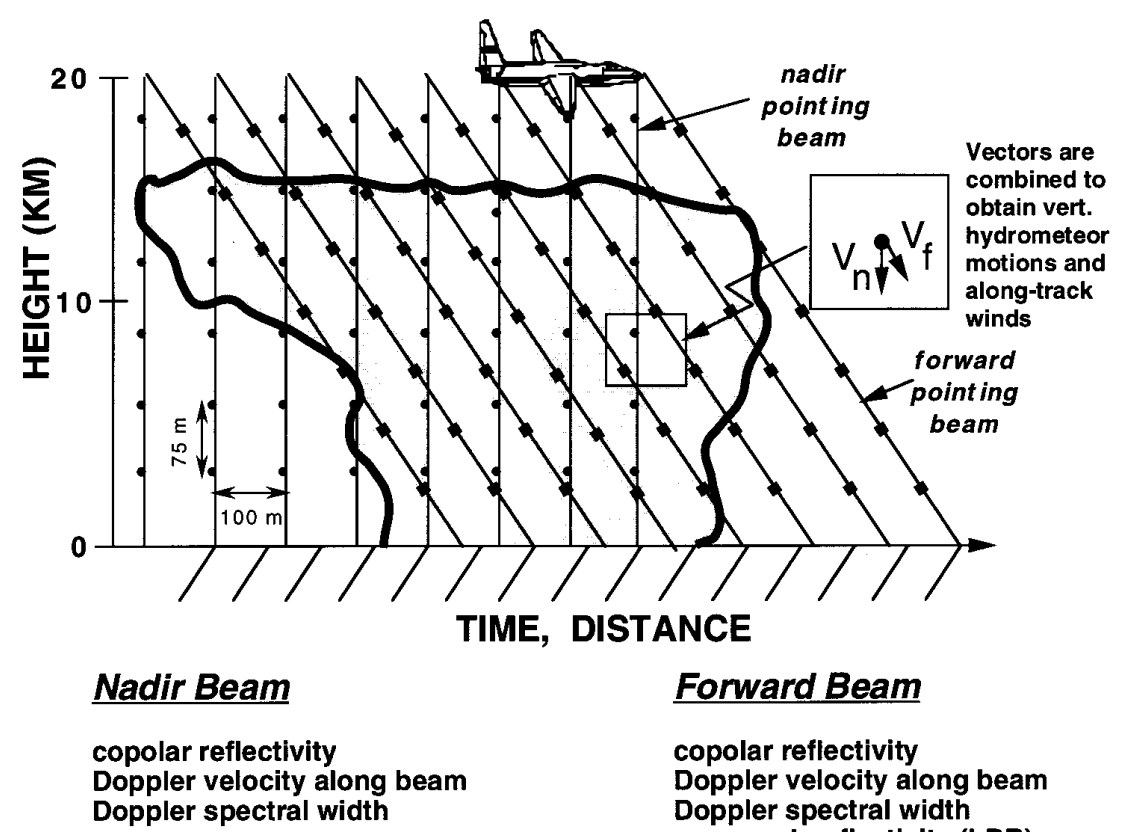

Forward Beam

copolar reflectivity

Doppler velocity along beam

Doppler spectral width

cross-pol. reflectivity (LDR)

FIG. 1. EDOP measurement concept.

understanding various algorithms for space-based observations (Adler et al. 1990; Smith et al. 1994; Heymsfield et al. 1995, etc.). Several studies have compared the ER-2 passive microwave measurements with the underlying hydrometeor structure using groundbased radars to improve the understanding of the microwave measurements (e.g., Fulton and Heymsfield 1991; Turk et al. 1994). EDOP-measured radar reflectivities coupled with the ER-2 passive microwave radiometeric temperatures will provide considerably better precipitation validation than is possible with ground-based radars.

The current paper provides a general description of the EDOP measurement concept, system configuration, and hardware, as well as some examples of recently obtained data. Along with other ER-2 remote sensing instruments, EDOP has several important precipitationoriented objectives: 1 ) to intercompare visible through high-frequency microwave passive radiometric temperatures with coincident radar measurements for assessing the limitations of various precipitation estimation algorithms, such as will be used in TRMM and other future spaceborne systems; 2) to better understand the microphysics and dynamics of deep precipitating systems such as differences in vertical structure between convective and stratiform regions; 3 ) to provide full coverage of MCSs, and 4) to evaluate new radar measurement techniques such as, for example, the proposed dual-beam rain retrieval approach for spaceborne rain measurements (Testud and Amayenc 1989).
Section 2 focuses on the EDOP measurement concept and will provide a discussion of the calculation of air motions from the Doppler measurements. Section 3 gives an overview of the system specifications resulting from the science requirements and an overview of the EDOP microwave and data system hardware. Section 4 presents examples of recent reflectivity and Doppler measurements collected from flights along the United States gulf coast.

\section{Motivation for EDOP configuration \\ a. EDOP measurement concept}

The EDOP measurement concept (Fig. 1) makes use of two fixed radar beams: one pointed at nadir and the other pointed at approximately $33.5^{\circ}$ forward of nadir. A transmit pulse with vertical linear polarization is sent to both antennas. Reflectivity and Doppler information are received from both the nadir and forward antennas. The nadir antenna measures the copolarized reflectivity $Z_{n v v}$, Doppler velocity $v_{n}$, and Doppler spectral width $\sigma_{n}$, while the forward beam measures copolarized reflectivity $Z_{f v v}$, Doppler velocity $v_{f}$, spectral width $\sigma_{f}$, and the cross polarized return $Z_{f h v}{ }^{1}$ Here subscripts $v, h, n$, and $f$ denote

\footnotetext{
${ }^{1}$ Here, $Z$ is taken here to be the equivalent radar reflectivity factor normally denoted by $Z_{e}$, which is effectively the water equivalent value of the reflectivity factor for Rayleigh scattering since the complex index of refraction $\left|K^{2}\right|=0.93$ is assumed.
} 
vertical polarization, horizontal polarization, nadir beam, and forward beam, respectively; $v v$ indicates vertical transmit and vertical receive, and $h v$ indicates vertical transmit and horizontally polarized receive. Data are collected simultaneously from both beams as the ER-2 flies typical linear flight segments, thus providing independent time-height sections of the precipitation region with one pass of the aircraft. The high-altitude viewing perspective of EDOP and its close proximity to deep thunderstorm updrafts and downdrafts allows for relatively high-resolution vertical structure measurements when compared with typical ground-based radars.

The motivation for dual antennas on EDOP is threefold. First, the two beams can be used together to provide time-height sections of vertical and along-track air motions as will be described in more detail in the next section. Using aircraft ground-speed, these timeheight sections are readily interpreted as distanceheight cross sections, which are more meaningful meteorologically; time-height measurements are referred to as cross sections hereafter. The nadir beam $v_{n}$ is used to calculate cross sections of vertical air motions in the precipitation regions by removing aircraft motions and hydrometeor fallspeeds ( similar to Marks and Houze 1987). The forward beam $v_{f}$ can be used along with $v_{n}$ to estimate the along-track wind component at each level. The high-resolution two-dimensional wind and reflectivity time-height profiles provide useful information on vertical circulations in various phenomena such as squall lines. The EDOP system is nonscanning, and thus the wind component normal to the aircraft track cannot be obtained. Also, EDOP cross sections are along the aircraft flight track, and thus it is desirable to have coordinated flights with other airborne and ground-based radars that provide a more complete three-dimensional view of the precipitation under interrogation. With the above approach, the absolute accuracy of the vertical motion is ultimately limited by accuracies of the fallspeed estimates and aircraft motions. $^{2}$

Second, the dual beams on EDOP provide the opportunity to test the "stereographic" approach proposed by Testud and Amayenc (1989) for estimation of the specific attenuation $K$. In their approach, a precipitation cell is viewed from two angles of incidence by a dual-beam airborne radar. Their variational approach for estimating $K$ requires reflectivity observations from fore and aft views of an airborne radar. The stereographic technique has been validated with side-

\footnotetext{
${ }^{2}$ The surface, "direct," and "mirror image" returns are under study to determine their use in compensating for pitch and roll errors and estimation of aircraft vertical velocities. Testud et al. (1995) have used the velocity of the surface measured with airborne radar to determine systematic biases in the Doppler velocities due to navigation and other errors.
}

looking observations from the NOAA-WP3D airborne radar (Kabeche and Testud 1995), and it has been proposed for use in rain estimation from nadir-directed spaceborne radar (Testud and Amayenc 1989). Other approaches exist for estimating $K$, but the main advantage of the stereographic approach is that it provides $K$ without knowledge of drop size distributions and hydrometeor species. The dual-beam EDOP measurements on the relatively stable ER-2 aircraft provide an opportune dataset to test this approach. The nadir and forward antennas on EDOP also provide information on the path-integrated attenuation and other properties of the rain layer. These attenuation measurements are used in combination with the Doppler measurements for obtaining a more complete understanding of the interaction between the storm microphysics and dynamics.

Third, the forward beam that has a fixed, highquality polarization antenna, can be used to explore polarization techniques from the airborne platform. Polarization measurements have been made by downlooking airborne measurements and have provided useful microphysical information (Kumagai et al. 1993). On EDOP, the linear depolarization ratio (LDR) is obtained from the ratio of the received power at two orthogonal polarizations when a linearly polarized pulse is transmitted: $L D R=10$ $\log \left(Z_{f h v} / Z_{f v v}\right)$. LDR can provide information on particle nonsphericity and orientation, even at high incidence angles such as with the EDOP configuration. This measurement is related to particle axial ratio and refractive index, although for larger particles such as hail it is related to tumbling, which causes a large particle canting angle (e.g., Jameson 1987; Kumagai et al. 1993). From LDR, it is possible to infer particle phase and ice particle habit (e.g., graupel, snow, hail ). The LDR values are very low in the rain region $(<-30 \mathrm{~dB})$, large in the wet hail regions $(\sim-15$ $\mathrm{dB})$, and intermediate in the dry snow region $(\sim-25 \mathrm{~dB})$. This microphysical information is important for understanding MCSs and the interpretation of the other ER-2 remote sensing measurements.

\section{b. Relation of measured Doppler winds to air motions}

Calculation of Cartesian air motion components from the measured EDOP Doppler velocities requires removal of the aircraft motions and the hydrometeor fallspeeds. The subject has been dealt with for nadir viewing radars (Marks and Houze 1987; Heymsfield 1989 ) and in a more general fashion for scanning airborne radars (Lee et al. 1994) where equations are derived for relating the measured Doppler velocities to various aircraft platform-produced and air motion terms. The general equation for the EDOP forward and nadir Doppler velocity can be obtained from simplification of Lee et al.'s Eqs. (15) and (25) as follows: 


$$
\begin{aligned}
v_{r}= & \underbrace{\left[\begin{array}{l}
-\mathrm{GS}(\cos D \cos \tau \cos R \sin P-\sin D \sin R \cos \tau+\cos D \cos P \sin \tau) \\
+w_{p}(\sin P \sin \tau-\cos P \cos \tau \cos R)
\end{array}\right]}_{V_{\text {plane }}} \\
& +\underbrace{\left[\begin{array}{l}
u(-\cos H \sin R \cos \tau+\sin H \cos R \cos \tau \sin P+\sin H \cos P \sin \tau) \\
+v(\sin H \sin R \cos \tau+\cos H \cos R \cos \tau \sin P+\cos H \cos P \sin \tau) \\
\left.+\left(w-v_{t}\right) \sin P \sin \tau-\cos P \cos \tau \cos R\right)
\end{array}\right]}_{V_{\text {hydrometeor }}} \\
= & V_{\text {plane }}+V_{\text {hydrometeor }},
\end{aligned}
$$

where GS, $D, H, P, R$, and $\tau$ are the aircraft ground speed, drift angle, heading, pitch, roll, and tilt angle of the antennas off nadir, respectively. Also, the three Cartesian wind components are denoted by $u, v$, and $w$, the aircraft vertical motion $w_{p}$, and the radar pulsevolume averaged hydrometeor fall speed $v_{t}$ with the convention that $v_{t}>0$ for falling hydrometeors; $V_{\text {plane }}$ and $V_{\text {hydrometeor }}$ represent aircraft motion produced terms and hydrometeor motion terms, respectively. Note that for downlooking measurements along the aircraft track as in Fig. 1, the azimuth angle in Lee et al.'s Eq. (15) has been fixed at $-\pi$. For the EDOP nadir antenna $\tau$ $\sim 0^{\circ}$, and for the forward antenna, $\tau \sim 33.5^{\circ}$.

The ER-2 can generally fly stable, straight flight lines, which is advantageous for constructing two-dimensional (height-time) images of radar data. Roll angle typically varies less than $0.25^{\circ}$ on straight flight lines, but on occasion it may have variations $\pm 1^{\circ}-2^{\circ}$ with periods of about $10 \mathrm{~s}$ near intense thunderstorms. The ER-2 angle of attack varies by about $2^{\circ}$ during a 6-7-h flight as a result of fuel burnoff, and although the pitch angle is relatively constant, it can be perturbed by as much as $\pm 2^{\circ}$ near thunderstorms. At the 20 - $\mathrm{km}$ ER-2 altitude, the ambient winds are typically very weak $\left(<5 \mathrm{~m} \mathrm{~s}^{-1}\right)$ so that drift angles are relatively small $\left(<1.5^{\circ}\right)$. This relative stability of the aircraft reduces the magnitude of the aircraft component of the correction to the data. However, it is still large enough to have a profound effect on air motion calculations. The parameters GS, $D, H, P$, and $R$ are provided by the navigation system on the ER-2, and $w_{p}$ is calculated in postflight analysis from vertical acceleration data using a pressure altitude feedback loop similar to that used by Scott et al. (1990).

Calculation of air motions from the measured Doppler velocities first requires removal of the aircraft motions $\left(V_{\text {plane }}\right)$ from (1). Equation (1) can be simplified for the EDOP measurements by setting $H=\pi / 2$, so that the $u^{\prime}$ horizontal component is defined along the aircraft heading, and $D=0$ and $R=0$ since they are typically near zero and they produce only a small cor- rection to $V_{\text {plane }}$ in (1). The forward and nadir Doppler winds can then be given by

$$
\begin{aligned}
& v_{n}=u^{\prime}\left(\cos \tau_{n} \sin P_{n}+\cos P_{n} \sin \tau_{n}\right) \\
& \quad+\left(w-v_{t}\right)\left(\sin P_{n} \sin \tau_{n}-\cos P_{n} \cos \tau_{n}\right) \\
& \begin{aligned}
v_{f}=u^{\prime}\left(\cos \tau_{f} \sin P_{f}+\cos P_{f} \sin \tau_{f}\right) \\
\quad+\left(w-v_{t}\right)\left(\sin P_{f} \sin \tau_{f}-\cos P_{f} \cos \tau_{f}\right)
\end{aligned}
\end{aligned}
$$

Here, the nadir and forward tilt angles are given by $\tau_{n}$ $\sim 0^{\circ}$ and $\tau_{f} \sim 33.5^{\circ}$. Assuming the Doppler velocities from the two beams are mapped to a common timeheight grid and the aircraft three-dimensional motions have been removed from the measured nadir $v_{n}$ and forward $v_{f}$ Doppler velocities, the approximate equations for the along-track $u^{\prime}$ component and the vertical velocity $w$ are given by

$$
\begin{gathered}
w=v_{t}+\frac{c_{1 n} v_{r f}-c_{1 f} v_{r n}}{c_{2 n} c_{1 f}-c_{2 f} c_{1 n}} \\
u^{\prime}=\frac{c_{2 n} v_{r f}-c_{2 f} v_{r n}}{c_{2 n} c_{1 f}-c_{2 f} c_{1 n}},
\end{gathered}
$$

where $c_{1 i}=\left(\sin P_{i} \cos \tau_{i}+\cos P_{i} \sin \tau_{i}\right), c_{2 i}=\left(\sin P_{i}\right.$ $\left.\times \sin \tau_{i}-\cos P_{i} \cos \tau_{i}\right)$, and $i=n$ and $f$ for nadir and forward beams, respectively. Note that calculation of the $u$ ' component requires only $v_{n}$ and $v_{f}$, and does not require $v_{t}$. Vertical air motions $(w)$ are obtained by removing hydrometeor motions using a $v_{t}$ estimate from an empirical $Z-v_{t}$ relations for rain and snow similar to Marks and Houze (1987), where a snow, rain, and intermediate transition region is defined. While the calculation of $w$ in (4) uses $v_{n}$ and $v_{f}$, the $u^{\prime}$ term of $v_{n}$ in (5) is small and $w$ can be estimated using only $v_{n}$. Another special case exists when the antenna is stabilized at nadir $\left(\tau_{n} \sim-P\right)$, which implies simplification to $w$ $\sim v_{t}-v_{n}$. The largest errors in estimating the alongtrack wind component are due to 1) storm structure evolution in the time between the forward and nadir looks, and 2) displacements between the forward and nadir beam locations due to a nonzero ER-2 drift angle or heading changes. 


\section{EDOP instrument overview}

\section{a. Specifications}

The science objectives for EDOP provided the basis for the hardware design. Since no single radar could satisfy all the scientific requirements, given the size and weight constraints of the ER-2 aircraft, a tradeoff analysis was performed prior to development of the system. Calculations were made to determine the optimum operating frequency to cover a wide range of precipitation situations. An important requirement for the system was to provide surface reference measurements for calibration purposes. The surface also provides a means to calibrate the antenna pointing angles that, if in error, will bias the Doppler velocities according to (1). The X-band frequency $(9.6 \mathrm{GHz})$ and $25-\mathrm{kW}$ peak power ( $12.5 \mathrm{~kW}$ per antenna) were found to satisfy most of the requirements, given that higher frequencies can have severe attenuation in high-reflectivity regions, and lower, less attenuating frequencies require too large an antenna for the ER-2. The general specifications for EDOP are given in Table 1 and are briefly described in the following.

Pulse repetition frequency (PRF) selection is dictated by the maximum unambiguous velocity to be accommodated, the desired velocity precision (which requires that PRF be maximized), and the maximum desired slant range from the radar. A PRF of $4400 \mathrm{~Hz}$ results in a Nyquist velocity $(=\mathrm{PRF} \lambda / 4)$ of $34.4 \mathrm{~m} \mathrm{~s}^{-1}$ and a maximum unambiguous range $(=c / 2 \mathrm{PRF})$ of $34.1 \mathrm{~km}$. This PRF provides the best compromise for cases where the updrafts are large such as in the midwestern United States thunderstorms, for the large $v_{f}$ resulting from the $200 \mathrm{~m} \mathrm{~s}^{-1}$ ER-2 horizontal translation, and for sufficient range to reach the surface from the 20-km ER-2 altitude. The lower 2200-Hz PRF ( Nyquist velocity $17 \mathrm{~m} \mathrm{~s}^{-1}$ and maximum range of $68 \mathrm{~km}$ ) is available for cases when EDOP is used for groundbased measurements when longer slant ranges are desired.

The transmit pulse widths are selectable from 0.25 to $1.0 \mu \mathrm{s}$, which results in range sampling intervals from 37.5 to $150 \mathrm{~m}$. For most of the precipitation measurements, vertical resolution of $75 \mathrm{~m}$ or better is desired. The received signal sensitivity is proportional to the pulse width: doubling the pulse width improves sensitivity by $6 \mathrm{~dB}$ but cuts the range resolution in half. ${ }^{3}$ The present configuration of EDOP is for a $1-\mu$ s maximum pulse width, but the system was designed for a maximum pulse width of $2 \mu \mathrm{s}$ as determined by the $0.1 \%$ duty cycle of the

\footnotetext{
${ }^{3}$ A 6- $\mathrm{dB}$ improvement results because there is a 3- $\mathrm{dB}$ increase in signal power and the hardware employs a bandpass filter matched to the transmit pulse, which improves the noise floor by an additional $3 \mathrm{~dB}$.
}

TABLE 1. EDOP system specifications.

\begin{tabular}{|c|c|}
\hline \multicolumn{2}{|l|}{ Transmitter } \\
\hline Frequency (wavelength) & $9.6 \mathrm{GHz}(3.123 \mathrm{~cm})$ \\
\hline Peak power (nominal) & $25 \mathrm{~kW}$ \\
\hline Pulse width & $0.25,0.5,1.0 \mu \mathrm{s}(0.5 \mu$ s typ. $)$ \\
\hline $\begin{array}{l}\text { Pulse repetition frequency } \\
\text { (PRF) } \\
\text { Traveling wave tube } \\
\text { amplifier (TWTA) }\end{array}$ & $2200,4400 \mathrm{~Hz}$ (4400 Hz typ.) \\
\hline \multicolumn{2}{|l|}{ Receiver } \\
\hline IF bandwidth & $60 \mathrm{MHz}$ \\
\hline $\begin{array}{l}\text { Dynamic range with gain } \\
\text { control }\end{array}$ & $110 \mathrm{~dB}$ \\
\hline $\begin{array}{l}\text { Minimum detectable signal } \\
\text { at } 10 \mathrm{~km}\end{array}$ & $-5 \mathrm{dBZ}$ (for $0.5-\mu \mathrm{s}$ pulse width) \\
\hline Linear Doppler channels & 2 \\
\hline Log. reflectivity channels & 3 \\
\hline IF filter bandwidth & $2,8 \mathrm{MHz}$ \\
\hline \multicolumn{2}{|l|}{ Antennas } \\
\hline $\begin{array}{l}\text { Type: offset fed parabolic } \\
\text { reflector using } \\
\text { "matched feed", } \\
\text { concept }\end{array}$ & \\
\hline Antenna diameter & $0.76 \mathrm{~m}$ \\
\hline Antenna beamwidth & $2.9^{\circ}$ \\
\hline Gain & $36 \mathrm{~dB}$ \\
\hline First sidelobe level & $<-26 \mathrm{~dB}$ \\
\hline Cross-polarization level & $<-30 \mathrm{~dB}$ \\
\hline $\begin{array}{l}\text { Nadir transmit/receive } \\
\text { polarization }\end{array}$ & $\mathrm{V} / \mathrm{V}$ \\
\hline $\begin{array}{l}\text { Forward transmit/receive } \\
\text { polarization }\end{array}$ & $\mathrm{V} / \mathrm{V}$ and $\mathrm{H}$ \\
\hline \multicolumn{2}{|l|}{ Data processing } \\
\hline $\mathrm{A} / \mathrm{D}$ converters & 7 channels $\times 12$ bits, $2 \mathrm{MHz}$ \\
\hline Signal processors & $24 \times$ AT\&T DSP32C \\
\hline Doppler processing type & pulse pair \\
\hline Gate spacing & $37.5,75,150$ m (75 m typ.) \\
\hline Gates & 436 (reflect.), 360 (Doppler) \\
\hline Integration cycle & $0.25-1.0 \mathrm{~s}(0.5 \mathrm{~s}$ typ. $)$ \\
\hline \multicolumn{2}{|l|}{ Products } \\
\hline Nadir & $Z_{n v v}, v_{n}, s_{n}, \mathrm{SNR}_{n}$ \\
\hline Forward & $Z_{f v v}, Z_{f h v}, v_{f}, s_{f}, \mathrm{SNR}_{f}$ \\
\hline Total system weight & $180 \mathrm{~kg}$ \\
\hline Total system input power & $1500 \mathrm{~W}$ \\
\hline
\end{tabular}

traveling wave tube (TWT) and the high-voltage power supply design.

A narrow antenna beamwidth is desirable for improved resolution of small-scale features in convective and other regions and for better accuracy of the Doppler velocity estimates. The EDOP offset-fed antennas with pencil beams are the largest apertures $(0.76 \mathrm{~m})$ and smallest beamwidths $\left(2.9^{\circ}\right)$ that could be installed in the ER-2. For the nadir beam, the effective beam shape is degraded slightly from circular to oblong along-track, due to averaging multiple radar pulses in the process of obtaining reflectivity or velocity estimates. The forward beam pulse volumes are tilted by $33.5^{\circ}$, and thus the vertical structure is slightly smeared and some loss of data occurs near the surface due to partial beam filling over several gates by surface re- 
turn. ${ }^{4}$ The uncertainty in the mean Doppler velocity estimates increase for larger beamwidths due to aircraft motion, although this is not of significant magnitude to be of concern for EDOP (see below).

Radar observations of intense thunderstorms require a large receiver dynamic range since the entire storm can encompass a dynamic range of greater than $80 \mathrm{~dB}$. Maximum reflectivities can approach $65 \mathrm{dBZ}$, the upper ice regions of the storm may be characterized by values less than $0 \mathrm{dBZ}$, and reflectivity gradients can approach $60 \mathrm{~dB} \mathrm{~km}^{-1}$. As a result, this wide dynamic range places stringent requirements on the receiver. The logarithmic receiver used in EDOP is capable of 80-dB dynamic range as presently implemented. Hardware exists for a computer-controlled automatic gain control (AGC) to improve the receiver dynamic range and prevent saturation for the strongest signals.

Estimation of the uncertainty of the EDOP reflectivity and Doppler measurements requires calculation of the number of independent samples integrated during a radar dwell. The coherence interval, or the time to independence or decorrelation time $T_{i}$, is determined either from the random motion of the scatterers within the radar pulse volume, the beam broadening, and the time required for the aircraft to move a distance equal to the spatial footprint of the antenna. The latter aircraft translational effect has a fairly long decorrelation time on the order of a few seconds. The decorrelation due to reshuffling of meteorological targets and to beam broadening may be derived, based on the Doppler spectral width $\sigma_{v}$ given according to $T_{i}=2 \lambda / \sigma_{v}$, where $T_{i}$ is in units of milliseconds, $\lambda$ is in centimeters, and $\sigma_{v}$ in meters per second (e.g., Sauvageot 1992). For the EDOP parameters (Table 1), this corresponds to $T_{i} \sim 2 \mathrm{~ms}$ assuming a $\sigma_{v}$ of $3.4 \mathrm{~m} \mathrm{~s}^{-1}\left(\sigma_{v}\right.$ is calculated below). Based on these estimates, there are approximately 250 independent samples for a typical 0.5 s dwell.

The accuracy of the reflectivity measurements from EDOP can be estimated as follows. For video matchedfiltering, the Rayleigh fading signal statistics evolve into a chi-squared distribution with mean $\bar{P}$ and standard deviation $\sigma(\bar{P})=\bar{P}(2 N)^{-1 / 2}$ (Davenport and Root 1987, Eq. 12-23), where $N=250$ is the number of statistically independent samples for a 0.5 -s dwell. Thus, $\sigma(\bar{P}) \approx 4.5 \%$ of $\bar{P}$ and the one-sigma uncertainty in the reflectivity data, averaged over a typical $0.5-\mathrm{s}$ dwell is $10 \log [1 \pm \sigma(\bar{P})]=0.2 \mathrm{~dB}$. Note that an exact calculation would be based on an assumed form for the

\footnotetext{
${ }^{4}$ The vertical beam dimension $V$ of the forward beam can be given by $V=R \sin \mathrm{BW} \sin \tau+L \cos \tau$, where $R$ is the range from the aircraft, $\tau=33.5^{\circ}, L=75 \mathrm{~m}$ is the pulse length, and $\mathrm{BW}=2.9^{\circ}$ is the $3-\mathrm{dB}$ beamwidth of the antenna. For a $20-\mathrm{km}$ aircraft altitude, $R=24 \mathrm{~km}$ for the forward beam resulting in $V=620 \mathrm{~m}$. The number $N$ of forward beam range gates affected by the surface is $N=R \mathrm{BW} \tan \tau /$ $L=11$ gates; thus, about 6 gates above the surface are affected by the surface return. These calculations neglect sidelobes, which would increase $V$ and $N$.
}

signal correlation properties. This measurement represents a relative uncertainty and the absolute accuracy of the reflectivity measurements are determined by the precision of the calibration. Recent flights have indicated absolute calibration accuracy to better than $2 \mathrm{~dB}$ from comparison to ground-based radar (Caylor et al. 1994).

The uncertainty in the Doppler velocity estimates can be given as follows. For autocovariance processing, which is used in EDOP for Doppler velocity and spectral width estimation, the mean Doppler velocity measurement uncertainty $\sigma_{\bar{v}}$ for large signal-to-noise ratios and narrow spectral widths is given by

$$
\sigma_{\bar{v}}^{2}=\frac{\sigma_{v} \mathrm{PRF} \lambda}{8 M \sqrt{\pi}},
$$

where $M$ is the number of pulse-pairs [Eq. (6.23) in Doviak and Zrnić 1993]. The uncertainty of the mean Doppler velocity is increased for broader Doppler spectra under the assumption of Gaussian and non-Gaussian spectra. The total Doppler spectral width of precipitation return is primarily a function of beam broadening due to aircraft motion, wind shear, turbulence, and fall velocity distribution. Doppler spectral broadening results from the aircraft horizontal motion, which produces a cross-beam wind component. The standard deviation of this beam broadening contribution for the nadir beam is given by $\sigma_{v}=0.3 B \mathrm{TAS}$, where $B$ is the antenna beamwidth between the 3-dB points, and TAS is the true airspeed (e.g., Atlas 1964; Sauvageot 1992).

$$
\begin{aligned}
\sigma_{v}= & {\left[\sigma_{v}^{2}(\text { beam broad })+\sigma_{v}^{2}+(\text { shear })\right.} \\
& +\sigma_{v}^{2}(\text { turbulence }) \\
& \left.+\sigma_{v}^{2}(\text { fallspeed distribution })\right]^{0.5} \\
\approx & {\left[\left(3.0 \mathrm{~m} \mathrm{~s}^{-1}\right)^{2}+\left(0.5 \mathrm{~m} \mathrm{~s}^{-1}\right)^{2}\right.} \\
& \left.+\left(1.0 \mathrm{~m} \mathrm{~s}^{-1}\right)^{2}+\left(1.0 \mathrm{~m} \mathrm{~s}^{-1}\right)^{2}\right]^{0.5} \\
\approx & 3.4 \mathrm{~m} \mathrm{~s}^{-1},
\end{aligned}
$$

where the beam broadening term is estimated above and reasonable estimates are made for the other terms. Using (6) with EDOP parameters and $M=2200$ pairs for 0.5 -s sampling dwells, the standard deviation of the mean Doppler velocity $\sigma_{\bar{v}}$ is roughly $0.1 \mathrm{~m} \mathrm{~s}^{-1}$, which exceeds the observational requirements of EDOP. This figure represents measurement precision; absolute accuracy, or systematic error characteristics arising from factors such as aircraft attitude errors are not included in this number. Note that for well-behaved wind distributions such as uniform linear wind shears across the radar beam, the spectral width is broadened and the accuracy of the mean Doppler velocity estimate degrades. The above estimate assumes relatively well-behaved Doppler spectra. This assumption may be invalid for highly non-Gaussian spectra such as when several spectral modes occur with small-scale subbeam scale 


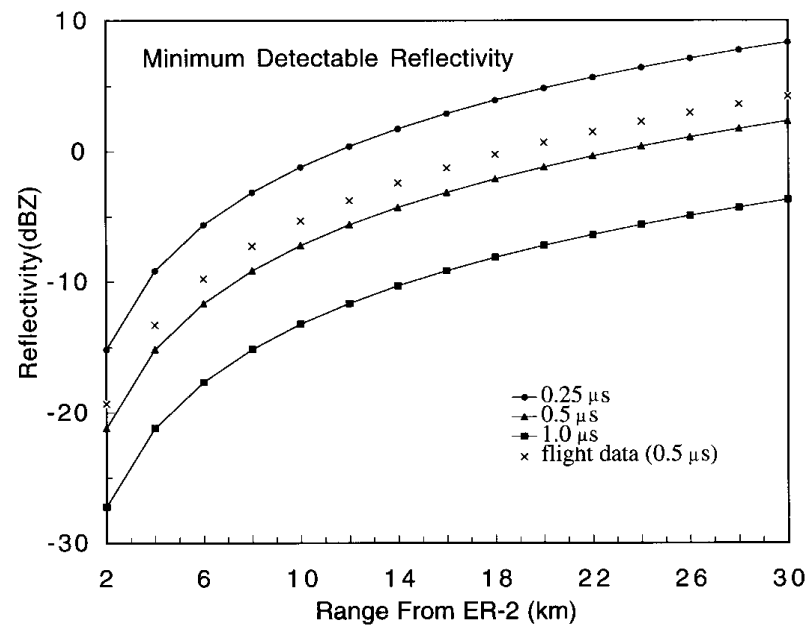

FIG. 2. EDOP minimum detectable reflectivity for $0.25-, 0.5-$, and $1.0-\mu$ s pulse widths. Theoretical curves are given along with a curve based on actual measurements.

air motions or widely disperse particle distributions such as associated with hail.

Finally, an important aspect of the radar system is its sensitivity to weak cloud regions, such as in ice regions near cloud top and weak rain near the surface. While there are a number of different methods to calculate the sensitivity of radar systems, the approach used here calculates the minimum detectable signal $\bar{P}_{\min }$ based on a noise power level for the system and the number of independent samples. After substituting the EDOP parameters (Table 1) into the radar equation as described by Caylor et al. (1994), an equation is obtained to convert $\bar{P}_{\min }$ to an equivalent radar reflectivity factor. EDOP employs an IF filter bandwidth matched to the transmit pulsewidth and therefore losses associated with a matched filter (e.g., Doviak and Zrnić 1993 ) must be accounted for in the radar equation. The $\bar{P}_{\text {min }}$ is obtained from the mean noise power for EDOP, which can be given by $\bar{P}_{n}=k T_{0} B_{n}\left(F_{n}-1\right)=k T_{s} B_{n}$, where $k$ is Boltzman's constant, $T_{0}=290 \mathrm{~K}$ is the physical antenna temperature, $T_{s}$ is the system noise temperature, $F_{n}$ is the system noise figure, and $B_{n}$ is the noise bandwidth (Skolnik 1990). For EDOP, $F_{n}$ $=-1.8 \mathrm{~dB}, B_{n}=2 \mathrm{MHz}$, which results in $T_{s}=437.6$ $\mathrm{K}$ and $\bar{P}_{n} \sim-109 \mathrm{dBm}$. According to Atlas (1964), for greater than 10 independent samples and a $97.3 \%$ confidence limit, the minimum detectable signal can be distinguished from the average noise at a level $\bar{P}_{\min }$ $=2 \bar{P}_{n}\left(N^{1 / 2}-1\right)^{-1}=-117 \mathrm{dBm}$. Using this $\bar{P}_{\text {min }}$ value for the $0.5-\mu \mathrm{s}$ pulse width case in the radar equation provides estimates of the EDOP minimum detectable reflectivity shown in Fig. 2; curves for two other pulse width settings $(0.25$ and $1.0 \mu \mathrm{s})$ are also shown. These curves indicate reasonably good sensitivity near cloud top and for weak rain near the surface. Actual $\bar{P}_{\text {min }}$ mea- surements are about $2 \mathrm{~dB}$ lower than the above estimate.

\section{b. RF hardware description}

The EDOP system is configured for operation in a refurbished military radar nose for the ER-2. Among the system operational concerns are 1 ) severe environmental conditions, 2) limited pilot interaction, and 3 ) size and weight restrictions, impacting the electronics. Conditions within the nose of the ER-2 present a difficult environment for electronic instrumentation. In particular, air temperatures of $-20^{\circ} \mathrm{C}$ and partial pressurization of $0.3 \mathrm{~atm}(9.1-\mathrm{km}$ altitude) are typical of ambient conditions in the ER-2 nose. Single pilot operation complicates instrument design since only two switches and two indicator lights are available during flight for instrument power-up, monitor, and control. The entire radar system must therefore have the capability to function in a "turn key" mode, with internal monitoring of any faults that may occur in the transmitter or data system, and the capability to reset the system automatically in the event that a recoverable system failure is detected.

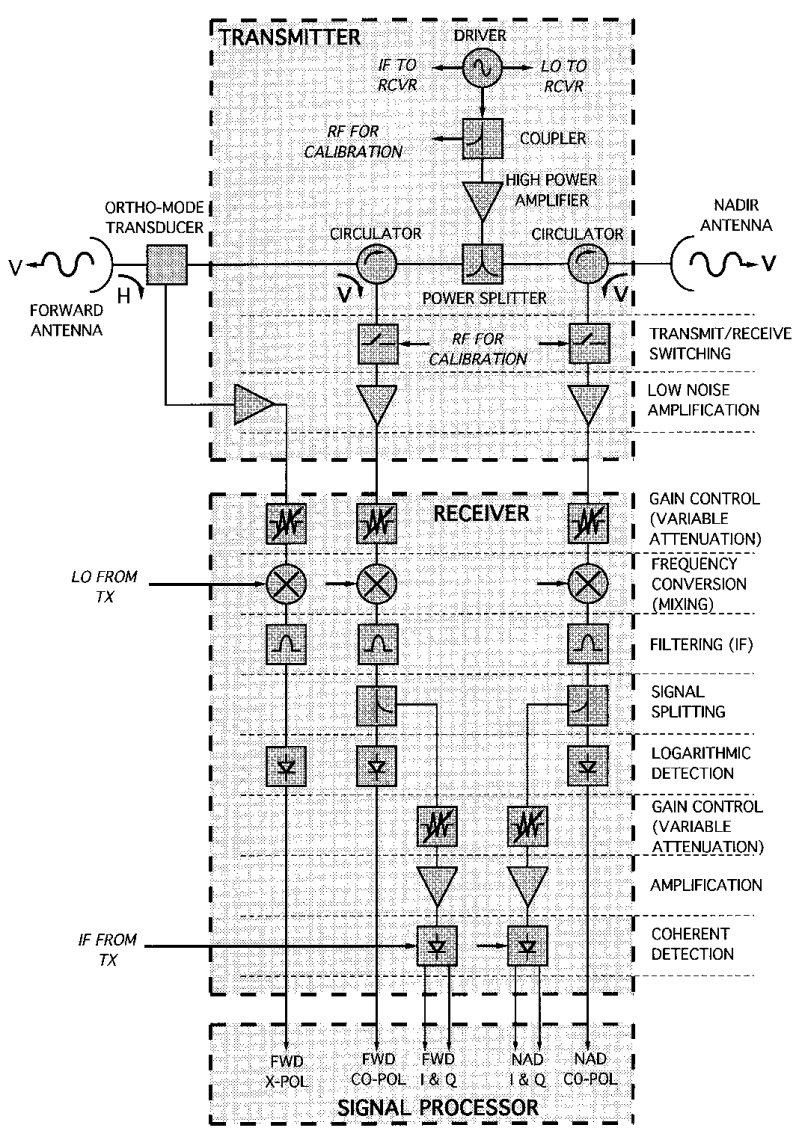

FIG. 3. Simplified block diagram of EDOP in ER-2 nose cone. 
A simplified block diagram of EDOP is shown in Fig. 3, and the layout of the entire system in the ER-2 nose is shown in Fig. 4. The RF system consists of transmitter and receiver subsystems that are housed in two separate enclosures. The principal system components that govern spectral purity of the Doppler signal are the reference oscillator (or system clock), the phase-locked oscillators, and the TWTA (traveling wave tube amplifier) and related power supply.

The EDOP transmitter consists of 1) two phaselocked oscillators, one at $9.66 \mathrm{GHz}$ (local oscillator, $\mathrm{LO}$ ) and the other at $60 \mathrm{MHz}$ (intermediate frequency, IF), both locked to a $10-\mathrm{MHz}$ reference oscillator, 2) an exciter circuit generating the $0.25-1.0 \mu$ s pulsed drive signal at the coherent transmit frequency (9.6 $\mathrm{GHz}$ ) to the power amplifier, and 3 ) a high gain 25 $\mathrm{kW}$ Litton air-cooled TWTA with output coupled through a power divider and cascaded Ferrite circulators to the antennas. The peak transmit signal is split (reducing power per channel by $3 \mathrm{~dB}$ ) for simultaneous transmission through the nadir and forward antennas. Both the oscillator and TWTA phase-noise levels are negligible in comparison to the Doppler uncertainty for typical SNR values. Forced air is used to cool the TWTA. In order to reduce weight, sulfur hexaflouride is used in lieu of transformer oil to prevent high voltage breakdown in the transmitter high-voltage power supply compartment. The remainder of the transmitter enclosure and waveguides are filled with nitrogen to prevent condensation during aircraft descent and to prevent high-power microwave breakdown within the waveguides.

Following the received signal path, the receiver consists of 1) low-noise GaAs preamplifiers for the three received channels (nadir copolarized, forward co- and cross-polarized); 2) computer controlled RF variable attenuators providing automatic gain control (AGC); 3 ) mixers/IF preampliers to up-convert the received signal; 4) bandpass filters; 5) a splitter to divide the copolarized returns into logarithmic and to IF linear channels; 6) logarithmic detection and amplification on the reflectivity channels; 7) a computer controlled AGC on the linear (Doppler) channels; and 8) in-phase and quadrature detection on the linear channels. Separate logarithmic IF channels are used for acquisition of reflectivity data because of their inherently wide dynamic range $(80 \mathrm{~dB})$ of the logarithmic IF amplifiers and the convenience of logarithmic data acquisition. Because of their inherent nonlinear characteristics, logarithmic receivers are not suitable for Doppler processing and thus the linear channels for the nadir and forward antennas are processed separately. Though software has not yet been implemented, the option exists with the current hardware to implement a programmed AGC range profile that uses a priori knowledge of the reflectivity profile. AGC action is based on the average of several preceding range bins, so that the "local mean" of the Rayleigh fading signals can be estimated.

The EDOP antenna design consists of two separate offset-fed parabolic antennas mounted in the nose of the ER-2 to generate the downlooking and forwardbeams (Fig. 4). The antenna requirements for EDOP are for low sidelobes, high gain $(>35 \mathrm{~dB})$, and high polarization purity $(<-30 \mathrm{~dB}$ isolation $)$. The conventionally fed single offset reflector exhibits all of these features except for the cross-polarization performance. The short focal length required to fit the antennas in the EDOP nose further degrades the cross-polarization measurements. To overcome this disadvantage with the conventionally fed antenna, "trimode" feeds were used that employ focal plane field matching based on the "matched feed" concept (Rudge and Adatia 1975 ). With this technique, excellent polarization characteristics are achieved. The radome which covers the lower half of the ER-2 nose is designed for $9.6-\mathrm{GHz}$ transmission and is an " $A$ " sandwich design consisting of a low dielectric constant center core with thin reinforcing face sheets. Radio frequency testing of the curved radome with the offset parabolas has demonstrated low loss $(<0.25 \mathrm{~dB})$ at the EDOP transmit frequency.
SIDE VIEW

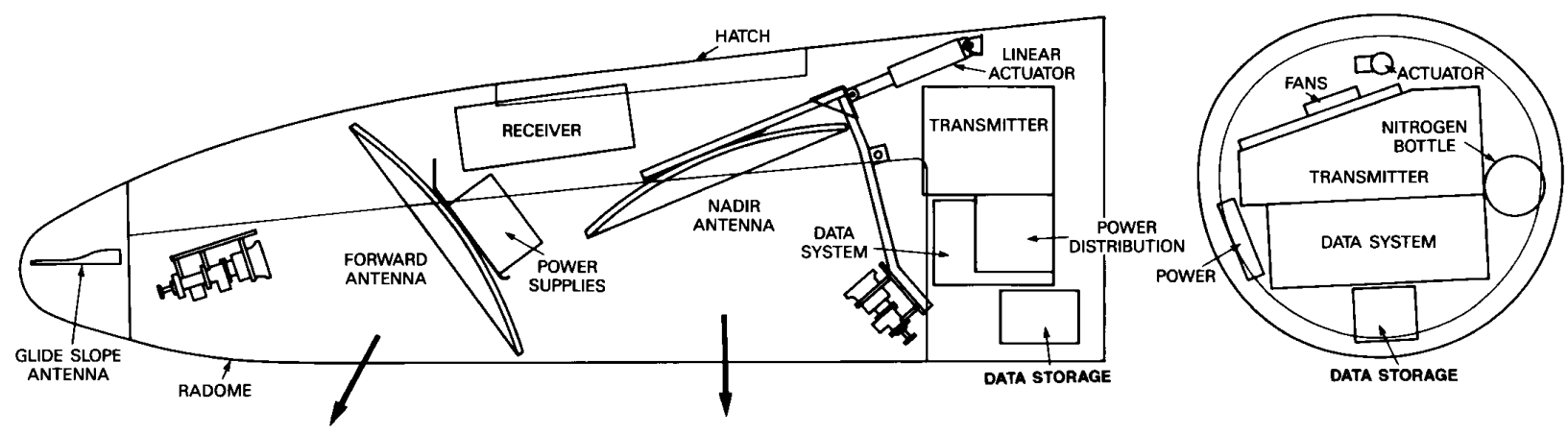

FIG. 4. Layout of EDOP system in ER-2 nose cone. 
The requirement to calculate air motions from the Doppler measurements by (1) has provided the motivation to stabilize the nadir antenna. The major correction to (1) before calculating $w$ is the terms involving aircraft motions $\left(V_{\text {plane }}\right)$. Heymsfield (1989) has suggested that horizontal winds $(u, v)$ in (1) which are not known a priori, can also introduce errors in $w$. A simple error analysis showed that without stabilizing the antennas for aircraft pitch variations, the worst case errors in $w$ excluding the error in the fallspeed would be about $0.5 \mathrm{~m} \mathrm{~s}^{-1}$. The nadir pointing beam has thus been designed for pitch stabilization (i.e., $P=-\tau_{n} \sim 0$ ), which simplifies (4) to $w=v_{t}-v_{n}$. Hardware currently exists for stabilization of the nadir antenna, but software has not yet implemented until further experience is obtained with the EDOP system and with a new highspeed navigation interface on the ER-2.

\section{c. Data system hardware and processing}

The data system addresses the analog-to-digital conversion of radar output, signal processing of data, acquisition of aircraft navigation data, storage of processed and housekeeping data, and overall control and initialization of the data system. Details of this data system and the hardware implementation of the processing algorithms are described in Nicholson (1994). The on-board real-time processing provides estimates of Doppler velocity, reflectivity, and spectral width. For Doppler processing, the dual-lag pulse-pair algorithm is used on the in-phase $(I)$ and quadrature $(Q)$ time series data (Srivastava et al. 1979). The processors perform reflectivity averaging and calculate the zeroth, first, and second lag complex autocovariances at each gate. The dual-lag pulse-pair estimates for the velocity and spectral width estimates are performed in postflight using the processed autocovariances. The real-time processor for EDOP is designed to accommodate the extremely high data and processing rates required by the system's $4400-\mathrm{Hz}$ PRF, the four linear (i.e., two Doppler $I$ and $Q$ pairs ) and three logarithmic receiver channels, $37.5-\mathrm{m}$ range resolution $(0.25 \mu \mathrm{s})$, 0.5 -s dwell times. The current implementation provides processing all channels simultaneously for a PRF of $4400 \mathrm{~Hz}, 436$ gates, and $0.5-\mathrm{s}$ dwells. Note that the EDOP processor requirements are somewhat higher than those for typical ground-based systems since the EDOP PRF is about four times that of these systems and both beams are being processed simultaneously. The processing of the mean received power for the three reflectivity estimates is performed with samples from the logarithmic receiver channels. The bias introduced by logarithmic integration is removed in postprocessing (Zrnić 1975).

The data system is based on a VME chassis with a 68030 host computer that provides basic control and initialization of the system. The host computer queues processed radar returns and aircraft navigation data to a 2-Gbyte disk drive, which is housed in a pressurized enclosure. The radar interface and control function is handled by a custom-designed radar interface board (RIB). The analog-to-digital conversion of the linear $(I, Q)$ and $\log$ (reflectivity) channels is achieved with two custom designed four-channel, $2 \mathrm{MHz}$ per channel, 12-bit acquisition boards. The signal processing is performed with three $\mathrm{C}$ programmable processing boards developed by Martin Marietta, which use eight AT\&T DSP-32C chips to provide 200 Mflops of computational capability per board. The digitized data from the seven channels is distributed over two high-speed buses (each 40 Mbyte $^{-1}$ ) by the RIB to the 24 digital signal processing (DSP) zones on the three processor boards. The processing boards then calculate the reflectivity means and the first three lags of the complex autocovariance required for the pulse-pair velocity and spectral width calculation. These processed values are read along with status and navigation information by the host computer over the VME bus and merged into a single datastream prior to data storage.

As discussed earlier, accurate aircraft attitude and position information is required for removal of the three-dimensional aircraft motion vector from the Doppler measurements in postflight analysis. The ER2 is equipped with a Litton LTN-92 inertial navigation system (INS) with Global Positioning System (GPS) update. The high-speed navigation data from the INS is distributed to the ER-2 instruments on the aircraft over two ARINC-429 buses. EDOP has an additional VME board to capture high-speed (up to $64 \mathrm{~Hz}$ ) navigation data for each dwell of radar data along with the processed radar measurements and status information. Currently, 123 parameters of navigation data are stored at the 0.5-s dwell intervals. The data system also has custom interfaces for automatic gain control to achieve larger dynamic range in the logarithmic and linear receiver channels and pitch control of the nadir antenna. These items, although existing in hardware, have not yet been implemented in software.

\section{d. Calibration procedures}

The calibration procedure for EDOP reflectivity measurements is described in detail in Caylor et al. (1994). Calibration of EDOP receiver involves converting the received power from engineering units in digitized counts to physical units $(\mathrm{dBm})$. A radar constant incorporating fixed parameters in the radar equation was calculated for each receiver channel based on EDOP parameters and measured losses in the receiver chain. Reflectivities (dBZ) are calculated by combining the radar constant, the measured received power, and the range-squared correction. EDOP calibration is typically performed in the laboratory by injecting known RF power levels into the antenna ports prior to and after a deployment. During flight, the calibration stability of the three RF receivers is checked at regular 
intervals (typically $30 \mathrm{~min}$ ) using an internal calibration routine that injects a continuous wave signal into the receiver front-ends. Long-term stability of the transmitter power also affects the overall calibration. This measurement is accomplished indirectly since the high power transmitted pulse, although significantly attenuated, leaks through the circulator and transmit-receive switch into the receiver. Since the data system begins sampling just prior to the leading edge of the transmit pulse, the transmit pulse is sampled qualitatively throughout the flight. Calibration data from both the receiver and transmitter have shown stability to within about $0.25 \mathrm{~dB}$ during flight after an initial 3045-min warmup period following takeoff. Caylor et al. (1994) have shown that the EDOP calibrated reflectivity agrees to within a few decibels with data from the Melbourne, Florida, WSR-88D radar. The ocean surface scattering cross section $\sigma_{o}$ has also been used to validate the calibration. The nadir and forward antennas that are beamwidth and pulse length limited, respectively, require different forms of the radar equation for $\sigma_{o}$ calculations (Eqs. 2-39 and 2-40 in Nathanson 1969). Recent flights of EDOP have provided additional confidence in the receiver stability and the absolute reflectivity calibration.

Calibration of the antenna pointing angles is important for using both the reflectivity and Doppler measurements from EDOP. The EDOP antennas do not scan, and thus to estimate the mounting angles of the antennas, the ER-2 occasionally performs calibration manuevers during level, cloud-free flight over the ocean in which the aircraft pitches up and down by approximately $5^{\circ}$ and subsequently rolls left and right by about $10^{\circ}$. These manuevers provide a means to estimate antenna tilt (pitch) and azimuth (roll) mounting angles from variations in the surface echo Doppler velocity (Testud et al. 1995). In addition to these manuevers, flight tracks during ascent and descent, where pitch angles were greater than $5^{\circ}$, were also examined. For the observations presented later, the forward and nadir tilt angles were estimated to be within $0.1^{\circ}$ of $33.5^{\circ}$ and $1.4^{\circ}$, respectively. The azimuth angle for both nadir and forward antennas were determined to be less than $0.5^{\circ}$; roll angle biases cannot be estimated more accurately since they produce only small variations in the measured Doppler velocities [see (1)]. No attempts were made to separate the antenna mounting angles from absolute deviations in the INS. This will not affect calculations using (1) since the Doppler velocity is dependent on the sum of the pitch and tilt angles.

\section{EDOP observations}

EDOP collected its first data from the Convection and Atmospheric Moisture Experiment (CAMEX) based at Wallops Island, Virginia, during September and October 1993. The ER-2 carried a full suite of radiometers ranging from visible to microwave wave- lengths during this deployment. EDOP was still in a development mode for CAMEX and was set up to record primarily raw reflectivity measurements that were averaged in postflight analysis. On one of the flights during CAMEX, data were collected from a group of thunderstorms on 5 October 1993 in the southern Florida region. Results intercomparing the EDOP reflectivity measurements along with microwave and infrared radiometric measurements for this case have been reported in Heymsfield et al. (1995).

A series of flights based out of Houston called Houston Precipitation Experiment (HOPEX) were conducted during January 1995. EDOP operated with full reflectivity and Doppler processing for the first time. During a flight on 13 January 1995, the ER-2 overflew an intense squall line with an extensive stratiform region along the Gulf Coast. The squall line developed in the western part of the gulf during the early morning hours and advanced eastward to beyond Mobile, Alabama at the time of the ER-2 overpass ( $\sim 1800$ UTC). Some hail was reported with this squall line and there were a number of strong surface wind gusts reported prior to the squall-line passage, although no extensive damage was reported with this line. Figure 5 provides reflectivity images from the nadir beam during the outgoing flight leg. The data have been calibrated using a radar constant derived as in Caylor et al. (1994) but modified for several configuration changes during HOPEX. The ER-2 flew at 19.4-km altitude during which the surface return remained roughly in the same range gate. The aircraft was quite stable during this flight line with pitch, roll, and drift values of $-0.62^{\circ}$ $\pm 0.44^{\circ},-0.13^{\circ} \pm 0.04^{\circ}$, and $-0.12^{\circ} \pm 0.91^{\circ}$, respectively. Ranges greater than $19.4 \mathrm{~km}$ from the ER-2 that include features such as "mirror image" returns are truncated in Fig. 5 for presentation purposes. Also, the data display has been thresholded to a minimum received power of $-110 \mathrm{dBm}$, which corresponds to a minimum detectable reflectivity of $1 \mathrm{dBZ}$ at $10-\mathrm{km}$ altitude. Note the bottom panel (240-340-km distance) has a different reflectivity scale because the reflectivities are much lower than the other panels. The figure shows a leading convective region at about $25-\mathrm{km}$ distance with tops extending to about $12 \mathrm{~km}$, a westward tilt, and peak reflectivities of about $55 \mathrm{dBZ}$. An extensive trailing stratiform region is evident between 100 and $200 \mathrm{~km}$ with a well-defined bright band and peak reflectivities near $50 \mathrm{dBZ}$. The bright band is centered at about $3 \mathrm{~km}$ close-in to the convective region, but abruptly undergoes lowering by about $500 \mathrm{~m}$ at $160 \mathrm{~km}$ distance. A trailing anvil ice layer (240- and 340-km distance) is apparent between 4- and 9-km altitude with maximum reflectivities of about $25 \mathrm{dBZ}$ near $5-\mathrm{km}$ altitude. Considerable small-scale structure is present in the observations such as precipitation streamers 2-3 $\mathrm{km}$ across below the melting level.

Figure 6 presents "gridded" nadir and forward reflectivity and nadir Doppler velocity with aircraft mo- 

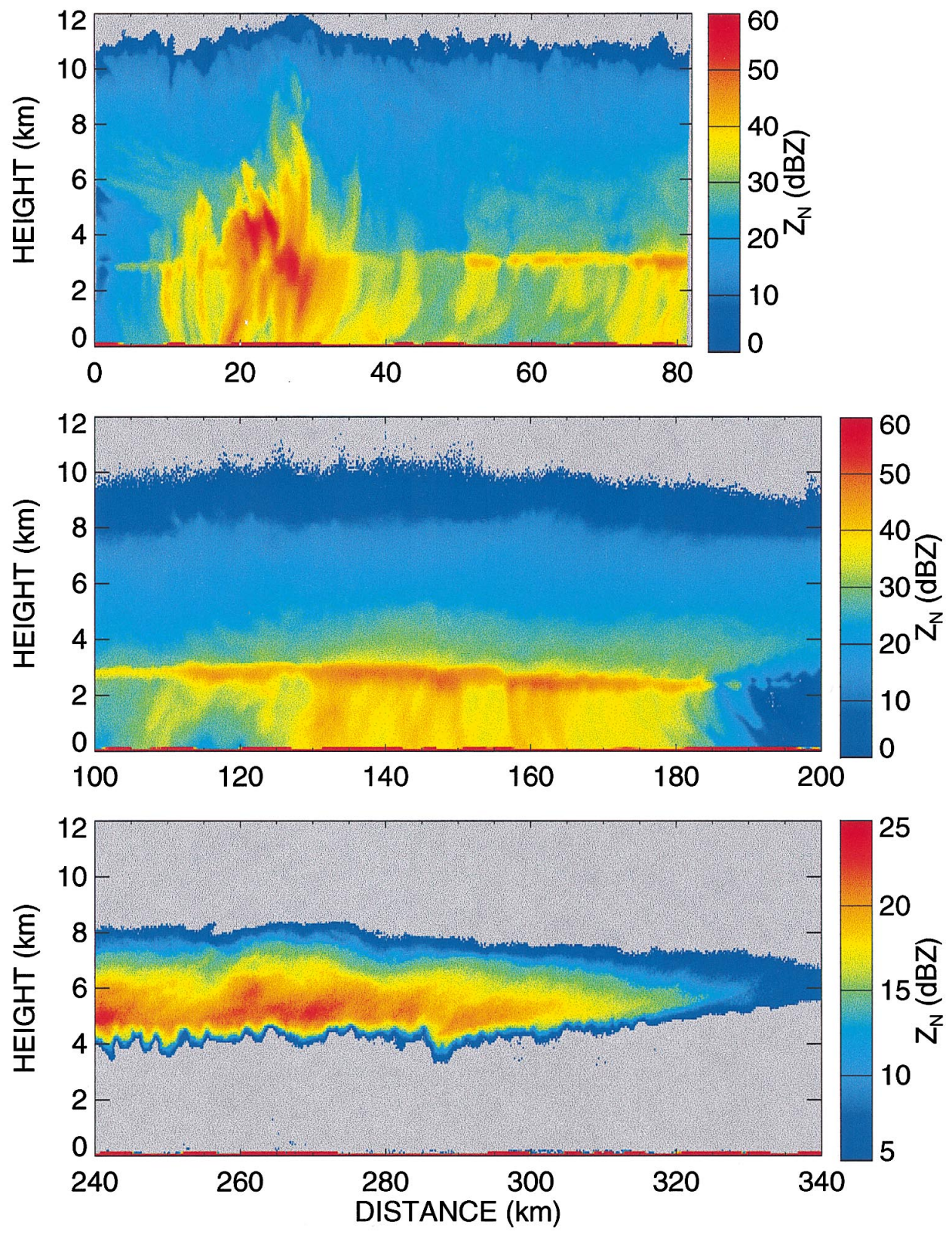

FIG. 5. Nadir reflectivity $Z_{n}$ cross section covering full 360-km width ( $\sim 30 \mathrm{~min}$ ) of 13 January 1995 squall line. Convective region is located at $25-\mathrm{km}$ distance (top panel), stratiform region between 100 and $200 \mathrm{~km}$ (middle panel), and thin trailing anvil cirrus is at $0-100-\mathrm{km}$ distance (bottom panel). Distance increases toward the east. Bottom panel has different color scale.

tions removed [i.e., $V_{p}$ term in (1)] for the same squall line convective region in Fig. 5. The nadir and forward beam radar data have been mapped to common grids to facilitate later wind and reflectivity analyses using the dual-beam information. This gridding is accomplished in several steps as follows. First, the gate containing the surface peak echo is determined for every nadir and forward dwell. For each range gate, an $x$ (along-track distance) $-z$ (height) pair relative to the aircraft reference frame is computed using the pitch, roll, drift, antenna tilt, and slant range information in the track-relative coordinate transformation derived by Lee et al. (1994). The $z$ coordinate for each gate is offset by the $z$ value at the surface, thus giving height about the surface. A flat earth is assumed, which is valid for the EDOP geometry, where the forward beam at the surface is only $13 \mathrm{~km}$ ahead of the subnadir point. The $x$ coordinates are incremented by the distance trav- 

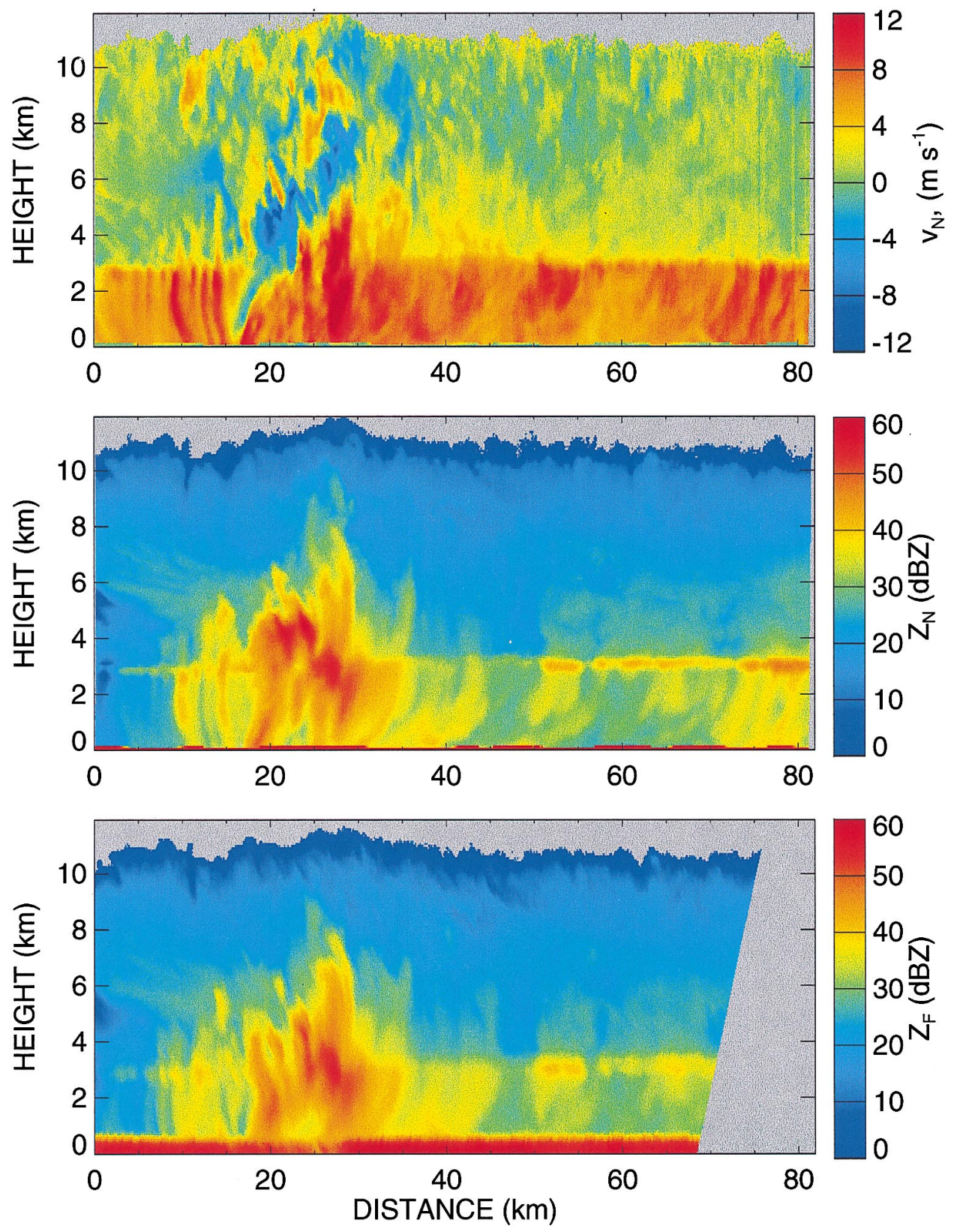

FIG. 6. Convective region cross sections from the squall line shown in Fig. 5 for nadir hydrometeor motions $V_{\text {hydrometeor }}$ (top panel), nadir reflectivity $Z_{n}$ (middle panel), and forward reflectivity $Z_{f}$ (bottom panel). The Doppler velocities have aircraft motions removed and represent hydrometeor motions with positive velocities downward. The forward reflectivity has been remapped into its true projection using aircraft attitude information.

eled from some reference time such as the beginning of the flight line (i.e., the product of the elapsed time and the ER-2 ground speed). Finally, the forward and nadir data are interpolated onto a regularly spaced rectangular grid using linear interpolation.

The nadir and forward reflectivity panels in Fig. 6 are similar qualitatively. Prominant features such as the bright band and high reflectivity cores in the convective region are reasonably similar between the two beams. Major differences between the two fields are primarily attributed to 1) changes and/or advection in the storm structure in the interval between forward and nadir observation, and 2) attenuation along the propagation path. In the convective regions of the squall line (20- 
$\mathrm{km}$ distance), there is up to $17 \mathrm{~dB}$ of attenuation on the nadir channel and $12 \mathrm{~dB}$ of attenuation on the forward (Caylor et al. 1995). The attenuation on the two paths accounts for the differences in structure in the regions of high precipitation. A few additional differences between the forward and nadir reflectivity images are also apparent. The forward beam is more smeared out in the vertical due to the $33.5^{\circ}$ tilt of the radar pulse volumes ( see footnote 4 ). The ocean surface is evident in images, but for the forward beam, the high reflectivity surface return covers roughly 15 gates total in lowreflectivity regions, as a result of the surface return entering into the antenna main beam and sidelobes (see footnote 4). Another difference between the nadir and forward reflectivities is in the height of the echo tops. This can be totally attributed to the forward beam having about $2 \mathrm{~dB}$ less sensitivity than the nadir beam, which results in lower detected cloud tops.

The Doppler velocity panel in Fig. 6, which provides hydrometeor motions $\left[V_{\text {hydrometeor }}\right.$ in (1)], shows an obvious increase in velocities from above $\left(1-2 \mathrm{~m} \mathrm{~s}^{-1}\right)$ to below the bright band $\left(>6 \mathrm{~m} \mathrm{~s}^{-1}\right)$ due to the increase in fallspeeds from snow to rain. Considering that the updraft region has reflectivities greater than $45 \mathrm{dBZ}$, the particle fallspeeds are likely to be at least $5 \mathrm{~m} \mathrm{~s}^{-1}$ using a $Z-v_{t}$ relation (e.g., Doviak and Zrnić 1993). With this in mind, a strong westward tilted updraft with a core maximum at least $15 \mathrm{~m} \mathrm{~s}^{-1}$ at $4-5-\mathrm{km}$ altitude is present, with downdrafts along the periphery of the updraft core. The squall-line updraft region is comprised of a number of discrete reflectivity and hydrometeor motion pulses rather than being continuous. This may be partially explained by the way in which the cross section intersects the updraft region, particularly if the updrafts are three-dimensional rather than two-dimensional. Marks and Houze (1987), using nadir and zenith beams from the NOAA WP3 tail radar data, have provided vertical velocity estimates by removing hydrometeor motions $v_{t}$ using separate $Z-v_{t}$ relations for the snow, rain, and intermediate transition regions. The $v_{t}$ estimate is the most critical assumption in obtaining $w$, since $v_{t}$ depends on many factors such as particle phase, size distributions, etc. In rain regions, $v_{t}$ can be estimated within $1 \mathrm{~m} \mathrm{~s}^{-1}$ using $Z-v_{t}$ relations. But difficulty occurs in mixed-phase regions and when large ice particles (hail) are present and errors are somewhat larger. Another factor of relevance is that reflectivities are attenuated in the convective region and they must be corrected before using $Z-v_{t}$ relations. Initial attempts for correcting this attenuation have been reasonably successful (Caylor et al. 1995).

\section{Conclusions}

EDOP is a new Doppler radar system with a unique downlooking, high-altitude ER-2 viewing perspective. The radar operates at $9.6-\mathrm{GHz}$ wavelength and has fixed nadir and forward pointing beams that map out
Doppler winds and reflectivities in the vertical plane along the aircraft motion vector. Doppler winds from the two beams can be used to derive vertical and alongtrack air motions. The forward beam also provides polarization information. The dual-beam geometry and the Doppler and polarization capabilities provide the opportunity for interesting remote sensing studies relevant to spaceborne applications and to basic understanding of precipitation system structure. Future flights using EDOP combined with other remote sensing instruments will maximize the use of the EDOP observations. Preliminary data from the instrument is encouraging, with indications that most of the original science objectives are achievable. The reflectivity and Doppler observations have provided high-resolution vertical cross sections from squall lines and convective regions. Calculation of derived products such as alongtrack and vertical air velocities, attenuation retrieval from the dual-beam approach (Testud and Amayenc 1989), and linear depolarization measurements, will be reported in future papers. Methods to improve the accuracy of the along-track and vertical air motion estimates are currently being examined. Aircraft motions have been removed from the Doppler measurements using low data rate GPS climb rate estimates; highspeed navigation data from these flights will be used in the future, but the uncertainty in estimation of $v_{t}$ still remains the largest source of error in estimating $w$. Better methods to estimate $v_{t}$ are currently being explored using the information from the dual beams and the linear depolarization (LDR) measurements provided by EDOP.

Acknowledgments. The development of this instrument was a joint project between the Goddard Mesoscale Atmospheric Processes Branch and the Microwave Sensors Branch. It has involved a variety of efforts that deserve special recognition. Mr. R. Aldridge has provided invaluable technician services for the radar. Mr. M. Triesky is appreciated for his assistance on technical issues such as antenna testing. Efforts on the EDOP data system by the Goddard Microelectronics Branch are acknowledged. Pulse Technology of Marietta, Georgia is appreciated for supporting technical issues related to the radar microwave hardware. The NASA Ames High-Altitude Branch was responsible for the integration of the instrument on the ER-2 along with Lockheed engineers. Many other individuals have helped in one way or another. This work was supported under NASA's Mission To Planet Earth by Dr. Ramesh Kakar at NASA Headquarters.

\section{REFERENCES}

Adler, R. F., R. A. Mack, N. Prasad, H.-Y. Yeh, and I. M. Hakkarinen, 1990: Aircraft microwave observations and simulations of deep convection from 18 to $183 \mathrm{GHz}$. Part I: Observations. J. Atmos. Oceanic Technol., 7, 377-391.

Atlas, D., 1964: Advances in radar meteorology. Advances in Geophysics, Vol. 10, Academic Press, 317-478. 
Carbone, R. E., M. J. Carpenter, and C. D. Burghart, 1985: Doppler radar sampling limitations in convective storms. J. Atmos. Oceanic Technol., 2, 357-361.

Caylor, I. J., G. M. Heymsfield, S. Bidwell, and S. Ameen, 1994 NASA ER-2 Doppler radar reflectivity calibration for the CAMEX project. NASA Tech. Memo. 104611, 15 pp. [Available from NASA Center for Aerospace Information, 800 Elkridge Landing Rd., Linthicum Heights, MD 21090-2934].

,,--- , and -1995 : Estimating the rain rate profile in the presence of attenuation using EDOP airborne radar observations. Preprints, 27th Radar Meteorology Conf., Vail, CO, Amer. Meteor. Soc., 783-785.

Cotton, W. R., and R. A. Anthes, 1989: Storm and Cloud Dynamics Academic Press, 880 pp.

Davenport, W. B., Jr., and W. L. Root, 1987: An Introduction to the Theory of Random Signals and Noise. IEEE Press, 393 pp.

Doviak, R. J., and D. S. Zrnić, 1993: Doppler Radar and Weather Observations. Academic Press, 562 pp.

Durden, S. L., E. Im, F. K. Li, W. Ricketts, A. Tanner, and W. Wilson, 1994: ARMAR: An airborne rain-mapping radar. J. Atmos. Oceanic Technol., 11, 727-737.

Fulton, R., and G. M. Heymsfield, 1991: Microphysical and radiative characteristics of convective clouds during COHMEX. J. Appl. Meteor., 30, 98-116.

Griffin, V. L., A. R. Guillory, M. Susko, and J. E. Arnold, 1994 Operations summary for the Convection and Moisture Experiment (CAMEX). NASA Tech. Memo. TM-108445, 180 pp.

Heymsfield, G. M., 1989: Accuracy of vertical air motions from nadir viewing Doppler airborne radars. J. Atmos. Oceanic Technol., 6, 1079-1082

, I. J. Caylor, J. M. Shepherd, W. S. Olson, S. W. Bidwell, S. Ameen, and W. Boncyk, 1996: Structure of Florida thunderstorms using high-altitude aircraft radiometer and radar observations. J. Appl. Meteor., in press.

Hildebrand, P. H., C. A. Walther, C. Frush, J. Testud, and G. Baudin, 1994: The ELDORA/ASTRAIA airborne Doppler weather radar. Proc. IEEE, 82, 1873-1890.

Jameson, A. R., 1987: Relations among linear and circular polarization parameters measured in canted hydrometeors. J. Atmos. Oceanic Technol., 4, 634-645.

Jorgensen, D. P., M. A. LeMone, and B. J.-D. Jou, 1991: Precipitation and kinematic structure of an oceanic mesoscale convective system. Part I: Convective line structure. Mon. Wea. Rev., 119, 2608-2637

, T. J. Matejka, and J. D. DuGranrut, 1996: Multi-beam techniques for deriving wind fields from airborne Doppler radars. $J$ Meteor. Atmos. Phys., 59, 83-104.

Kabeche, A., and J. Testud, 1995: Stereoradar meteorology: A new unified approach to process data from airborne or ground-based meteorological radars. J. Atmos. Oceanic Technol., 12, $783-$ 799.

Kakar, R., Ed., 1993: Mission summary reports. NASA COARE, 236 pp. [Available from NASA Headquarters, Code YS, Washington, DC 20546-0001.]

Kumagai, H., R. Meneghini, and T. Kozu, 1993: Preliminary results from multiparameter airborne rain radar measurement in the western Pacific. J. Appl. Meteor., 32, 433-440.
Lee, W.-C., P. Dodge, F. D. Marks Jr., and P. H. Hildebrand, 1994: Mapping of airborne Doppler radar data. J. Atmos. Oceanic Technol., 11, 572-578.

Marks, F. D., Jr., and R. A. Houze Jr., 1987: Inner core structure of Hurricane Alicia from airborne Doppler radar observations. $J$. Atmos. Sci., 44, 1296-1317.

Nathanson, F. E., 1991: Radar Design Principles: Signal Processing and the Environment. McGraw-Hill, $720 \mathrm{pp}$.

Nicholson, S. R., 1994: The design and development of signal-processing algorithms for an airborne X-band Doppler weather radar. Remote Sensing Lab. Tech. Report 10540-1, University of Kansas, 124 pp. [Available from University of Kansas, 2291 Irving Hill Road, Lawrence, KS 66045-2969.]

Ray, P., 1990: Convective dynamics. Radar in Meteorology, D. Atlas, Ed., Amer. Meteor. Soc., 383-387.

Rudge, A. W., and N. A. Adatia, 1975: New class of primary-feed antennas for use with offset parabolic-reflector antennas. Inst. Elec. Eng. Electron. Lith., 11, 597-599.

Sauvageot, H., 1992: Radar Meteorology. Artech, 366 pp.

Scott, S. G., P. Buji, and K. R. Chan, 1990: The meteorological measurement system on the NASA ER-2 aircraft. J. Atmos. Oceanic Technol., 7, 525-540.

Simpson, J., R. F. Adler, and G. R. North, 1988: A proposed Tropical Rainfall Measuring Mission (TRMM) satellite. Bull. Amer. Meteor. Soc., 69, 278-295.

Skolnick, M., 1990: Radar Handbook. 2d ed. McGraw Hill, 2.12.68

Smith, E. A., X. Xiang, A. Mugnai, R. E. Hood, and R. W. Spencer, 1994: Behavior of an inversion-based precipitation retrieval algorithm with high-resolution AMPR measurements including a low-frequency $10.7 \mathrm{GHz}$ channel. J. Atmos. Oceanic Technol. 11, 858-873.

Smull, B. F., and R. A. Houze, 1987: Dual-Doppler radar analysis of a midlatitude squall line with a trailing region of stratiform rain. J. Atmos. Sci., 44, 2128-2148.

Srivastava, R. C., A. R. Jameson, and P. H. Hildebrand, 1979: Timedomain computation of mean and variance of Doppler spectra J. Appl. Meteor., 18, 189-194.

Testud, J., and P. Amayenc, 1989: Stereoradar meteorology: A promising technique for observation of precipitation from a mobile platform. J. Atmos. Oceanic Technol., 6, 89-108.

— P. H. Hildebrand, and W.-C. Lee, 1995: A procedure to correct for airborne Doppler radar data for navigation errors using the echo returned from the earth's surface. J. Atmos. Oceanic Technol., 12, 800-820.

Turk, J., J. Vivekanandan, F. S. Marzano, R. E. Hood, R. W. Spencer, and F. J. LaFontaine, 1994: Active and passive microwave remote sensing of precipitating storms during CaPE. Part I: Advanced Microwave Precipitation Radiometer and polarimetric radar measurements and models. Meteor. Atmos. Phys., 54, 3-27.

Wang, J. R., and Coauthors, 1994: Airborne active and passive microwave observations of Typhoon Flo. IEEE Trans. Geosci. Re mote Sens., 32, 231-242.

Zrnic, D. S., 1975: Moments of estimated input power for finite sample averages of radar receiver outputs. IEEE Trans. Aerospace Electron. Syst., AES-11, 109-113. 